\title{
Maternal and Fetal Prognosis of Evacuated Parturients in N'Djamena Mother and Child Hospital (Chad)
}

\author{
Lhagadang Foumsou 1,2*, Bray Madoué Gabkika',2, Foba Kheba², Sadjoli Damthéou ${ }^{1,2}$, \\ Salathiel Djongali ${ }^{2}$
}

${ }^{1}$ Department of Gynecology and Obstetrics, Faculty of Human Health Sciences, University of N'Djamena, N'Djamena, Chad

${ }^{2}$ N'Djamena Mother and Child Hospital, N'Djamena, Chad

Email: ^foumlhaga@gmail.com

How to cite this paper: Foumsou, L., Gabkika, B.M., Kheba, F., Damthéou, S. and Djongali, S. (2021) Maternal and Fetal Prognosis of Evacuated Parturients in N'Djamena Mother and Child Hospital (Chad). Open Journal of Obstetrics and Gynecology, 11, 263-271.

https://doi.org/10.4236/ojog.2021.113025

Received: December 9, 2020

Accepted: March 8, 2021

Published: March 11, 2021

Copyright $\odot 2021$ by author(s) and Scientific Research Publishing Inc. This work is licensed under the Creative Commons Attribution International License (CC BY 4.0).

http://creativecommons.org/licenses/by/4.0/

\section{(c) (i) Open Access}

\begin{abstract}
Introduction: All pregnant women are at risk of obstetric complications leading to high fetal-maternal mortality and morbidity. The aim of this work was to evaluate the maternal and fetal prognosis of evacuated parturients. Patient and Method: we conducted a prospective analytical survey for four months, from April $1^{\text {st }}$ to July $31^{\text {st }}, 2018$ in the Maternity of N'Djamena Mother and Child Hospital about the maternal and fetal prognosis of evacuated parturients. Any parturient evacuated or referred for obstetric complications was included. Study parameters were epidemiological, clinical, para-clinical, therapeutic and prognosis order. These parameters were analyzed in the SPSS 18 French version software. Results: Evacuated parturients represented 20\% of maternity admissions. The average age was 23.9 years, with extremes ranging from 15 and 43 years. They were uneducated in $72.9 \%$, primiparous in $46.8 \%$ of cases. The three delays were dominated by the $1^{\text {st }}$ delay, which represented $34.1 \%$ of cases. In this series, $26.3 \%$ parturients had presented obstetric complications. Preruptive syndrome was the most common complication with 29.3\% cases. Predisposing factors to maternal-fetal complications were low attendance antenatal care, late evacuation and distance travelled. The maternal mortality rate was $3 \%$. Fetal complications were observed in $28.3 \%$ of cases and the neonatal mortality rate was $24.6 \%$. Conclusion: The maternal and fetal complications of evacuated parturients are a real public health problem in our regions. The suppression of delays, capacity reinforcement of peripheral maternity and the periodic recycling peripheral centers to recognize obstetric emergencies will contribute to improve the maternal and fetal prognosis of evacuated parturients.
\end{abstract}




\section{Keywords}

Maternal and Fetal Prognosis, Evacuated Parturients, Obstetric

Complications, Mother and Child Hospital, N'Djamena, Chad

\section{Introduction}

The risk of death as result as pregnancy varies in different regions of the world, it is never zero: low in Europe and North America, it is still very high in Black Africa [1]. The World Health Organization (WHO) estimated that 287,000 maternal deaths occurred worldwide in 2010 [2]. This number, compared to that recorded in 1990 , represents a decrease of $47 \%$. However, $99 \%$ of these deaths continue to occur in developing countries and $85 \%$ in sub-Saharan Africa and South-East Asia. WHO reports a maternal mortality ratio (MMR) of 210 maternal deaths per 100,000 live births (LV) worldwide and 520 deaths per 100,000 live births in Africa [2]. In Chad, according to the results of the 2015 Demographic and Health Survey (EDST III) [3], the maternal mortality rate is 860 per 100,000 live births.

In 1994, WHO emphasized on the importance of the reference/evacuation and against reference system for pregnancy and childbirth care [4]. In Africa, long distance to reach reference maternity hospitals, late evacuations, non-medical evacuations and double referrals indicate a deficiency in the evacuation system [5]. Several authors report that obstetric evacuations are responsible for $20 \%$ $30 \%$ of complications and elevated maternal and fetal mortality [7] [8] [9].

It is crucial that women with suffer severe obstetric complications receive quality care provided by qualified personal in an appropriate environment with necessary drugs, equipment and standard infrastructures [2]. For this reason, an important place should be given to women's transfers to specialized centers to reduce maternal and fetal mortality. The objective was to evaluate the maternal and fetal prognosis of evacuated parturients.

\section{Patients and Methods}

We conducted a prospective analytical survey for four months, from 1 April $1^{\text {st }}$ to July $31^{\text {st }}, 2018$ in the Maternity of N'Djamena Mother and Child Hospital. It focused on the maternal and fetal prognosis of evacuated parturients. Any parturient evacuated for an obstetric emergency, cared in the maternity of N'Djamena Mother and Child Hospital whose gestational age was 28 weeks or more, and who agreed to participate in the study was included. Not included were all patients admitted for gynaecological emergencies; those with a gestational age less than 28 weeks of pregnancy or who delivered in another maternity or at home and those who refused to participate in the survey.

The variables studied were: age, education level, parity, number of antenatal care, gestational age, time spent home after symptoms appear, time spent in the referral/evacuation structure, reason for evacuation, modes of transport, distance 
travelled, diagnosis of admission to maternity, management, time between diagnosis and management in the maternity of N'Djamena Mother and Child Hospital, maternal and fetal prognosis. We have a data collection sheet to collect the variables studied. After explaining the interest of the study to parturient, we interviewed parturients for the data collection.

The analysis was made using the SPSS software. 18.0. Chi-square $\left(\mathrm{X}^{2}\right)$, test ( $\mathrm{p}$ $<0.05)$ was used to compare variables.

The limitations of the study were lack of awareness of the time between the onset of symptoms or signs and admission into the health structure, ignorance of the care administered in the structure of the first contact favored by the low level of education.

\section{Results}

\subsection{Frequency}

During the study period, we registered 495 evacuated parturients among 2473 parturients admitted in the maternity of N'Djamena Mother and Child Hospital giving a frequency of $20 \%$.

On the 495 evacuated parturients, 130 cases had presented obstetric complications, or $26.2 \%$.

\section{Maternal obstetric complications}

In this series, pre-rupture syndrome was the most common obstetric complication with 38 cases, either $7.6 \%$. We recorded 15 cases of maternal deaths among 495 evacuated giving maternal lethality rate of $3.1 \%$ (Table 1 ).

\subsection{Causes of Maternal Deaths}

The causes of maternal deaths were dominated by postpartum hemorrhage in 8 cases, or 53.4\%; followed by eclampsia in 5 cases, either $33.3 \%$ and acute pulmonary edema ( 2 cases, or $13.3 \%$ ).

\section{Obstetric complications and education level}

Concerning the schooling, parturients no schooled had developed most obstetric complications (116/361 cases, or $32.13 \%)$. We observed a statistically significant difference between association lack of education and the occurrence of obstetric complications $(\mathrm{p}=0.02)$ (Table 2$)$.

\subsection{Obstetric Complications and Antenatal Care}

Obstetric complications were more reported among parturient who had not practiced any antenatal care (82/139 cases, or $59 \%)$. The difference was statistically significant $(\mathrm{p}<0.001)$. Those who had realized four and more antenatal care had developed less obstetric complications (11.2\%) (Table 3).

Obstetric complications and the distance covered between the referring structure and the Mother and Child Hospital (MCH).

The average distance travelled was $35.4 \mathrm{~km}$ with extremes ranging 2 and 385 km (Table 4). 
Table 1. Distribution of evacuated parturients according to maternal obstetric complications.

\begin{tabular}{ccc}
\hline Complications maternelles & Effectif $(\mathrm{n}=495)$ & Percentage (\%) \\
\hline Pre-rupture syndrome & 38 & 7.6 \\
Eclampsia & 22 & 4.4 \\
Uterine rupture & 14 & 2.8 \\
Abruption placental & 11 & 2.2 \\
Coagulation intravasculaire disséminée & 7 & 1.4 \\
Injuries of cervix, vagina and perineum & 7 & 1.4 \\
Hemorrhage at delivery & 5 & 1.1 \\
Severe Preeclampsia & 4 & 0.8 \\
hemorrhagic placenta praevia & 4 & 0.8 \\
Acute edema of lungs & 3 & 0.6 \\
Death & 15 & 3.1 \\
Total & 130 & 26.2 \\
\hline
\end{tabular}

Table 2. Distribution of obstetric complications under to the educational level.

\begin{tabular}{|c|c|c|c|c|c|c|}
\hline \multirow{2}{*}{ Schooling } & \multicolumn{2}{|c|}{ Obstetric complications } & \multirow{2}{*}{ Total } & \multirow{2}{*}{$\begin{array}{c}\% \\
\text { Complications }\end{array}$} & \multirow{2}{*}{$\mathrm{Chi}^{2}$} & \multirow{2}{*}{$\mathrm{p}$} \\
\hline & Absents & Presents & & & & \\
\hline No schooled & 245 & 116 & 361 & 32.13 & 1.42 & 0.020 \\
\hline Primary & 29 & 8 & 37 & 21.62 & 0.44 & 0.050 \\
\hline Secondary & 71 & 4 & 75 & 5.33 & 0.01 & 0.931 \\
\hline University & 20 & 2 & 22 & 9.09 & 2.34 & 0.104 \\
\hline Total & 365 & 130 & 495 & & & \\
\hline
\end{tabular}

$\mathrm{Chi}^{2}=4.153 ; \mathrm{p}=0.02$.

Table 3. Distribution of obstetric complications depending to the number of prenatal visits.

\begin{tabular}{|c|c|c|c|c|c|c|}
\hline \multirow{2}{*}{$\begin{array}{c}\text { Number of } \\
\text { antenatal care }\end{array}$} & \multicolumn{2}{|c|}{ Obstetric complications } & \multirow[t]{2}{*}{ Total } & \multirow{2}{*}{$\begin{array}{c}\% \\
\text { complications }\end{array}$} & \multirow{2}{*}{$\mathrm{Chi}^{2}$} & \multirow{2}{*}{$\mathrm{p}$} \\
\hline & Absents & Presents & & & & \\
\hline 0 & 57 & 82 & 139 & 59 & 24.23 & 0.0000 \\
\hline $1-3$ & 197 & 34 & 231 & 14.71 & 14.55 & 0.0001 \\
\hline 4 and more & 111 & 14 & 125 & 11.2 & 2.58 & 0.1084 \\
\hline Total & 365 & 130 & 495 & & & \\
\hline
\end{tabular}

$\mathrm{Chi}^{2}=25.51 ; \mathrm{p}<0.001$.

Table 4. Distribution of obstetric complications according to distance travelled between the referring structure and the Mother and Child Hospital.

\begin{tabular}{|c|c|c|c|c|}
\hline \multirow{2}{*}{$\begin{array}{l}\text { Distance travelled between } \\
\text { referring structure and } \mathrm{MCH}\end{array}$} & \multicolumn{2}{|c|}{ Obstetric complications } & \multirow{2}{*}{ Total } & \multirow{2}{*}{$\begin{array}{c}\% \\
\text { complications }\end{array}$} \\
\hline & Absents & Presents & & \\
\hline$<50 \mathrm{~km}^{\star}$ & 340 & 86 & 426 & 20.18 \\
\hline $50 \mathrm{~km}-100 \mathrm{~km}$ & 14 & 22 & 36 & 61.11 \\
\hline $101 \mathrm{~km}$ and more & 11 & 22 & 33 & 66.66 \\
\hline Total & 365 & 130 & 495 & \\
\hline
\end{tabular}

${ }^{\star}$ Kilometers; $\mathrm{Chi}^{2}=558.513 ; \mathrm{p}<0.001$. 
Parturients who had travelled more than $50 \mathrm{~km}$ had developed more obstetric complications. The difference was statistically significant $(\mathrm{p}<0.001)$, there was a relationship between distance travelled and the occurrence of obstetric complications. The greater the distance, more parturients developed obstetric complications.

\subsection{Neonatal Complications}

In this series, of the 515 newborns, 140 cases had presented neonatal complications, either $27.2 \%$. These complications were dominated by neonatal death in 127 cases, or $90.71 \%$; followed by respiratory distress ( 9 cases, or $6.43 \%$ ) and prematurity (4 cases, or $2.86 \%$ ).

Neonatal complications and the distance travelled between the referring health facility and the Mother and Child Hospital (MCH).

Newborns of parturients who had travelled $101 \mathrm{~km}$ or more $(69.69 \%)$ had presented more neonatal complications than those of parturients who had travelled $50 \mathrm{~km}$ at $100 \mathrm{~km}$ (61.11\%). Similarly, those of mothers who had travelled $50 \mathrm{~km}$ at $100 \mathrm{~km}$ had developed more complications than newborns of parturients that had travelled less than $50 \mathrm{~km}(21.3 \%)$. The difference was statistically significant $(\mathrm{p}<0.001)$ (Table 5).

\subsection{Factors That Influenced the Fetal Prognosis/Complications}

Foetal prognosis/complications were influenced by distance travelled (34\%), maternal complications that alter materno-fetal exchanges such as eclampsia (12\%), retroplacental hematoma (16\%) and uterine rupture (8\%).

\section{Discussion}

\subsection{Frequency}

In this series, we reported a frequency of $20 \%$ evacuated parturients. This rate is similar to those of Tshabu-Aguèmon [6] in 2012 in Cotonou, Benin and Sepou [7] in Bangui, Central African Republic, which are $23.8 \%$ and $27.3 \%$ respectively. It is superior to those of other authors [8] [9] [10] [11] [12] who are in the range of $7.9 \%$ to $15.7 \%$. However, other series [13] [14] find higher rates ranging from $31.2 \%$ to $74 \%$. The frequency of obstetric evacuations is highly variable from one

Table 5. Distribution of neonatal complications according to the distance travelled between the referring health structure and the Mother and Child Hospital.

\begin{tabular}{|c|c|c|c|c|}
\hline \multirow{2}{*}{$\begin{array}{l}\text { Distance travelled between } \\
\text { referring structure and } \mathrm{MCH}\end{array}$} & \multicolumn{2}{|c|}{ Neonatal Complications } & \multirow{2}{*}{ Total } & \multirow{2}{*}{$\begin{array}{c}\% \\
\text { complications }\end{array}$} \\
\hline & Absents & Presents & & \\
\hline$<50 \mathrm{~km}$ & 351 & 95 & 446 & 21.3 \\
\hline $50 \mathrm{~km}-100 \mathrm{~km}$ & 14 & 22 & 36 & 61.11 \\
\hline $101 \mathrm{~km}$ and more & 10 & 23 & 33 & 69.69 \\
\hline Total & 375 & 140 & 515 & \\
\hline
\end{tabular}

$\mathrm{Chi}^{2}=54.548 ; \mathrm{p}<0.001$. 
country to another according to the distribution of health structures in the national territory, local expertise and the existence of technical platforms.

\subsection{Obstetrical Complications}

In this study 130 parturients, or $26.3 \%$, had obstetric complications. Most complications could be avoided if parturients made timely visits to health structures, if diagnosis then evacuations were made in the short time and if blood products were permanently available in the blood bank. This delay would be explained by the low level of education that not allowing to understand the danger signs and the incompetence of personal to make an exact and timely diagnosis.

\subsection{Educational Level of Evacuated Parturients}

The educational level was dominated by the no schooled with $72.9 \%$. Diarra Nama [9] also finds a predominance of no schooled in her series with a proportion of $82.1 \%$. This high rate of no schooled would be explained by lack of real girls' schooling policy in our regions and poverty pushing parents to favour marriage source of income at the expense of the girl's schooling.

In this study, 32.13\% of no schooled had developed obstetric complications. There was a statistically significant correlation between lack of schooling and the occurrence of obstetric complications $(\mathrm{p}=0.02)$.

\subsection{Antenatal Care}

In this survey, $28.08 \%$ parturients had not practiced any antenatal care. This rate is less than that of Foumsou [15] in 2015 in N'Djamena, Chad, which obtains rate of $37 \%$. This difference can be explained by the release of campaigns on the advantages and benefits of antenatal care conducted by associations and learned societies and the ministry of health public.

Obstetric complications were reported among parturients who have not practiced any antenatal care (59\% of cases). We observed a statistically significant relationship between the number of antenatal care and obstetric complications $(\mathrm{p}=0.000)$.

\subsection{The Distance Covered between the Referring Structure and the Mother and Child Hospital}

The average distance travelled by parturients from evacuation structures at mother and child hospital was $30 \mathrm{~km}$ with extremes ranging from $1 \mathrm{~km}$ to $900 \mathrm{~km}$. This mean distance can be superimposed on that of Lompo [16], Thiam [13], Berthe M [12], which obtain an average of $33 \mathrm{~km}, 48.01 \mathrm{~km}$ and $54.3 \mathrm{~km}$ respectively. This would be explained by the fact that the majority of evacuated parturients came from district hospitals and health centers in N'Djamena city.

Parturients who had travelled more than $50 \mathrm{~km}$ had developed more obstetric complications. There was a relationship between distance travelled and the occurrence of obstetric complications ( $p=0.000$ ). Diarra Nama [9] in Côte d'Ivoire, who highlighted the predominance of obstetric complications among patients 
who have travelled, more than $30 \mathrm{~km}$, made this observation.

\subsection{Maternal Mortality}

Fifteen maternal deaths were registered among evacuated parturients women, either lethality rate of $3.1 \%$. This rate joined those of some authors [8] [9] [12] who range from $2.6 \%$ to $3.6 \%$.

Other data from the literature [10] [12] [16] [17] report higher rates in the order of $4.3 \%$ to $8.79 \%$. The fifteen maternal deaths linked to obstetric evacuations in our study represent $83.33 \%$ of 18 deaths recorded during this period. This high maternal mortality of obstetric evacuations was reported in most African countries: Tshabu-Aguèmon [6] finds 29 to 35, or 82.85\% in Benin; Cissé M. L. et al. [14] finds 22 on 30, etheir 73.33\% in Senegal, Diallo F. B [18] in 1998 in Conakry, Republic of Guinea, notes 23 evacuated parturients in a total of 26 maternal deaths, or 88.46\%; Solofomalala [19] in 2007 in Fenerive, Madagascar, reports 5 out of 6 , be $83.33 \%$. This would be explained by the fact that the evacuated parturients have taken too long in the structures that evacuate or have travelled long distances, sometimes without venous approach, so they have more serious obstetric complications that can lead to death.

Hemorrhage was the first cause of maternal death in our study with 8 parturients on 15 cases, either $53.4 \%$. Most research conduct in Africa points out that hemorrhage is the first cause of maternal death. Cissé ML [14] and TshabuAguèmon [6] report $30 \%$ and $34.4 \%$ respectively of bleeding as a cause of maternal death.

\subsection{Neonatal Mortality}

In this work, we recorded 515 newborns, including 127 neonatal deaths, be $24.66 \%$. This rate is similar to that of Cissé M. L. et al. [14] which is $25.8 \%$. Some authors [6] [13] [15] report lower rates, ranging from $15.44 \%$ to $18.8 \%$. Other series [9] [16] [17] point to higher rates ranging from $28 \%$ to $49.5 \%$. Factors such as poor monitoring of labour at evacuated centers, evacuation delay and care, poor condition of roads connecting sanitary structures that extend have contributed to increase of neonatal and maternal mortality rates.

\section{Conclusions}

This survey shows that obstetrical evacuations are a real public health problem in our environment because the maternal-fetal prognosis is very reserved. They concern young women, especially primiparous, no schooled and who have not practiced antenatal care. The distance travelled has a negative influence on fetal and maternal prognosis.

The reduction of maternal and neonatal morbidity and mortality requires the standardization of reference or evacuation criteria on the basis of risk factors allowing the identification of high-risk pregnancies and childbirths, the training of peripheral health personal in the recognition of these factors, the education of 
women on the recognition of danger signs and on the risks incurred by them and their children. It also passes through rapid evacuation, rapid and adequate management of evacuated parturients and a rapprochement of health structures by creating gynaecological and obstetrical units in district hospitals.

\section{Conflicts of Interest}

The authors declare no conflicts of interest regarding the publication of this paper.

\section{References}

[1] World Health Organization (2017) Managing Complications in Pregnancy and Childbirth: A Guide for Midwives and Doctors. 2nd Edition, World Health Organization, Geneva, 436 p.

[2] International Federation of Gynecology and Obstetrics (2013) How to Conduct Maternal Death Reviews (MDR) Guidelines and Tools for Health Professionals. 45 p.

[3] Ministry of Plan and Cooperation (2016) National Institute of Statistics, Economic and Demographic Studies in N'Djamena-Chad Demographic Health Survey and Multiple Indicators Survey in Chad (EDS-MICS) 2014-2015. 231 p.

[4] Lankoandé, J., Ouédraogo, C.M.R. and Ouédraogo, A. (1997) Obstetric Health Evacuations and Feto Maternal Mortality in Burkina Faso. Tropical Medicine, 57, 311-316.

[5] Saizonou, J., Ouendo, E.M. and Dujardin, B. (2006) Audit of Maternal Deaths in Four Reference Maternities in Benin: Quality of Emergency Care, Causes and Contributing Factors. African Journal of Reproductive Health, 10, 28-40. https://doi.org/10.2307/30032469

[6] Tshabu-Aguèmon, C., Denakpo, J., Adisso, S., Mampassi, E. and de Souza, J. (2012) Maternal and Perinatal Mortality Related to Obstetrical Referrals to the C.U.G.O. of the CNHU-HKM in Cotonou. Review African Anesthesia Emergency Medicine, 17, 43-49.

[7] Sepou, A., Yanza, M.C., Nguembi, E., Dotte, G.R. and Nali, M.N. (2000) Analysis of Medical Evacuations in Gynaecology and Obstetrics in Bangui, Central African Republic. French Studies Research/Health Notebooks, 10, 399-405.

[8] Lokoussou, A., Adisso, S., Komongui, D.G., Lantoundji, C., Hounkpatin, B.I. and Perrin, R.X. (2003) Obstetrical References in Emergencies Situations: Prognosis Aspects. African Gynaecology and Obstetrics Society Journal, 2, 213-217.

[9] Diarra Nama, A.J., Angbo, O., Koffi, M.N., Yao, T.K. and Welfens Ekra, C. (1999) Morbidity and Mortality Related to Obstetric Transfers in the Bouaflé Health District in Ivory Coast. Sante Publique, 11, 193-201.

[10] Sepou, A., Goddot, M. and Ngbale, R. (2009) Evolution in the Frequency of Problems Related to Medical Evacuations to Gynaecology-Obstetrics Service in Bangui Community Hospital. Clinics in Mother and Child Health, 6, 10-12.

[11] Thera, T., Traore, Y. and Kouma, A. (2015) Problematic of the Reference and Counter-Reference System of Obstetric Emergencies and Community Implication in Bamako District. Mali Medical, 30, 34-37.

[12] Berthe, M., Diawara, F., Coulibaly, S., Maiga, B. and Iknane, A.G. (2013) Study of the Relationship between Maternal-Fetal Prognosis at the Distance Travelled and the Mode of Admission in the Keniéba Health District in Mali. Public Health Mali, 
3, 84-87.

[13] Thiam, O., Cissé, M.L. and Mbaye, M. (2013) The Problematic of Evacuated Parturients to Rural Areas in Senegal: Example of Hospital Center in Ndioum. CAMES Health Review, 1, 51-56.

[14] Cissé, M.L., Raad, B., Diouf, A., Wade, F. and Moreau, J.C. (2010) Record of Obstetric Evacuations in Kolda Hospital. Black African Medicine, 57, 37-43.

[15] Lompo, K., Hutin, Y.J.F., Traoré, G., et al. (1993) Morbidity and Mortality Related to Obstetric Medical Evacuations in Bobo-Dioulasso Hospital, Burkina Faso. Annal Belgian Medicine Society, 73, 153-163.

[16] Foumsou, L., Gabkika, B.M., Chingnabo, L., et al. (2016) Analysis of Factors Associated with Avoidable Maternal Deaths in N'Djamena. Mother and Child Hospital in Chad. African Journal of Integrated Health, 6, 13-17.

[17] Soltani, M.S., Bechir, A. and Souissim, M.B. (1991) Profile of Pregnancies Referred in Tunisian Sahel. French Review Gynecology Obstetrics, 86, 511-513.

[18] Diallo, F.B., Diallo, A.B., Diallo, Y., et al. (1998) Maternal Mortality and Lifestyle Risk Factors. Black African Medicine, 45, 723-728.

[19] Solofomalala, G.D., Randriamalalaarijaona, R.T., Rasendramino, M.H., Ratsivalaka, R. and Canonne, F. (2007) Gyneco-Obstetrical Emergencies in a Malagasy District Maternity Hospital. Tropical Review Surgery, 1, 67-70. 